\title{
Inclusão da triagem sorológica para Doença Celíaca em mulheres com infertilidade: uma medida pertinente.
}

\author{
Klajn, Amanda F. ${ }^{1}$
}

\section{Resumo}

Introdução: A infertilidade feminina, definida pela Organização Mundial da Saúde (OMS) como sendo a ausência de gravidez dentro do período de pelo menos um ano de atividade sexual frequente e desprotegida, conta com vasto repertório de possíveis causas, dentre as quais a causa Idiopática assume importante representação. Nesse contexto, a Doença Celíaca (DC) ganha importância por conta da sua prevalência aumentada em mulheres com infertilidade, especialmente no subgrupo sem causa aparente definida, conforme documentado por diversos autores. O objetivo deste trabalho é avaliar a contribuição da triagem sorológica para DC na diminuição dos chamados casos de Esterilidade sem Causa Aparente (ESCA), em mulheres com queixas de infertilidade, analisando-se a prevalência de DC especialmente nesse grupo de pacientes. Método: Revisão sistemática de artigos científicos nas bases de dados MEDLINE, LILACS, SciELO, Free Medical Journals, entre outros, utilizando-se como descritores: celiac disease, reproductive disorders, infertility, unexplained infertility, women, prevalence, sorological screening e seus equivalentes em português. Doze artigos cumpriram com os critérios de inclusão deste estudo e foram selecionados, publicados ao longo dos últimos 10 anos em língua inglesa e portuguesa, incluindo artigos originais e de revisão. Resultados: Entre as diferentes etiologias relacionadas à infertilidade, a causa idiopática representou uma parcela entre $10 \%$ e $30 \%$ dos casos, nos trabalhos analisados. Já a prevalência de DC em mulheres com infertilidade esteve entre, cerca de, $1,5 \%$ e $3 \%$, subindo esse intervalo no subgrupo 'sem causa aparente', ficando, aproximadamente, entre $4 \%$ e $8 \%$. Conclusão:

1 Graduanda em Medicina, pela Universidade Federal de Santa Maria. Email: afkamanda@gmail.com 
Levando-se em conta a prevalência elevada de doença celíaca em mulheres com desordens reprodutivas, considera-se justificável a inclusão do screening sorológico para DC nesse grupo de pacientes, especialmente para os casos em que não se encontram causas definidas para explicar o quadro.

Palavras Chave: doença celíaca, infertilidade, triagem sorológica, distúrbios reprodutivos, revisão de literatura. 